\title{
RESEARCH OF HETÉNYI PARÁZS F1 PAPRIKA IN CULTIVATION TECHNOLOGY VARIANTS
}

\author{
Tóth Horgosi Péter ${ }^{{ }^{*}}$ \\ 1, Department of Horticulture, Faculty of Horticulture and Rural Development, John von Neumann University, Kecskemét, Hungary
}

https://doi.org/10.47833/2020.1.AGR.020

\author{
Keywords: \\ Spice pepper \\ Seeding \\ Capsaicin \\ ASTA
}

\section{Article history:}

Received 10 Dec 2019

Revised 24 Jan 2020

Accepted 30 Jan 2020

\begin{abstract}
In my experiment I investigated the Hetényi Parázs F1 pepper using different cultivation techniques. I set up my experiment at Univer Product Zrt. In Szentkirály under field conditions. The cultivation technologies were: seedlings, mulch (mulch), mulch (foil) + foliage. The following measurements were taken after harvesting: yield, average berry weight, dry matter content, capsaicinoid content, dye content.
\end{abstract}

\section{Introduction}

The paprika contributed significantly to the foundation of the reputation of Hungarian cuisine. Its consumption increases the production of digestive juices, thereby improving digestion.

In addition to coloring agents, sugars and essential oils play an important role in the development of the characteristic aroma and taste of paprika.

Its significant role in nutrition is enhanced by its significant vitamin C, E and B content.

Spice peppers are not only used as a spice mill for seasoning, but are also consumed in the form of different paprika preparations.

They are sweet and spicy and contain paprika and occasionally pritamin paprika (Capsicum annuum var. Lycopersiforme) [1].

The intense and characteristic red color of Capsicum fruits is principally due to the pigments of capsanthin and capsorubin[2]. Capsaicinoids also have strong physiological and pharmacological properties. In addition to its widespread use as a neuropharmacological tool, capsaicin is of great medical value and it has been reviewed to evaluate its effect in treatment of painful conditions such as: rheumatic diseases, cluster headache, painful diabetic neuropathy, postherpetic neuralgia, etc. [3].

\section{Method}

Seeding took place on March 21, 2018. The seedlings were planted on May 18, 2018 in a twin row arrangement.

The experiment was planted in 4 replicates $(110+40 \mathrm{~cm}$ * $20 \mathrm{~cm})$. During the planting we used different technologies: seedling, mulching, mulching with foil.

The variety was harvested at two times on 24.08.2018 and 29.08.2018 in 4 replicates.

Only biologically ripe berries were harvested during the harvest.

A sample weight of $1 \mathrm{~kg}$ was collected from each replicate. After picking, we counted the number of berries in a kilo sample.

\footnotetext{
* Corresponding author. Tel.: +36 203254610

E-mail address: tohopeti@gmail.com
}

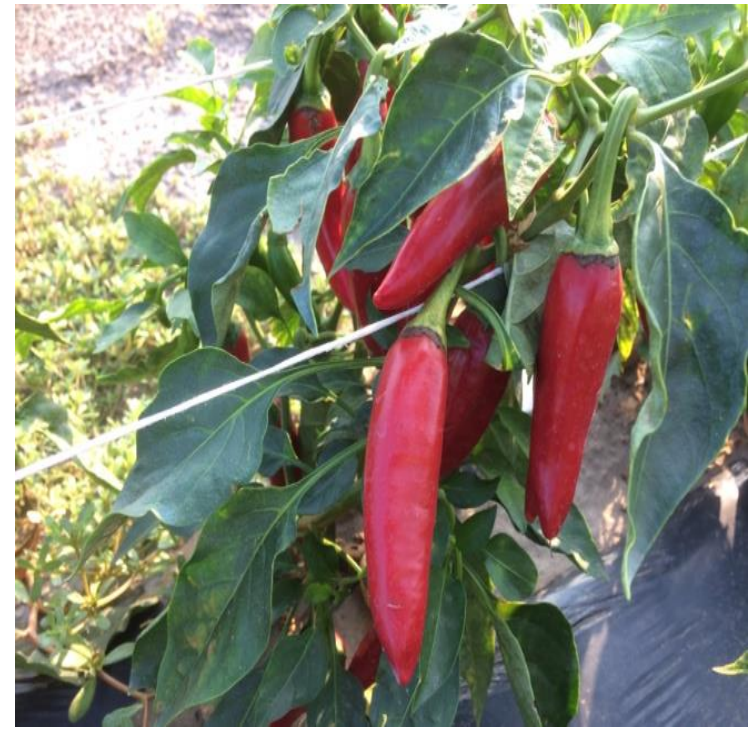

1.Figure Hetényi Parázs before the harvest 
After recording all measured data, the samples were dried for 40 days in a covered place. In our measurements the following parameters were examined: yield, dry matter at harvest, dry content at harvest, capsaicin content, average berry weight at harvest.

\section{Results}

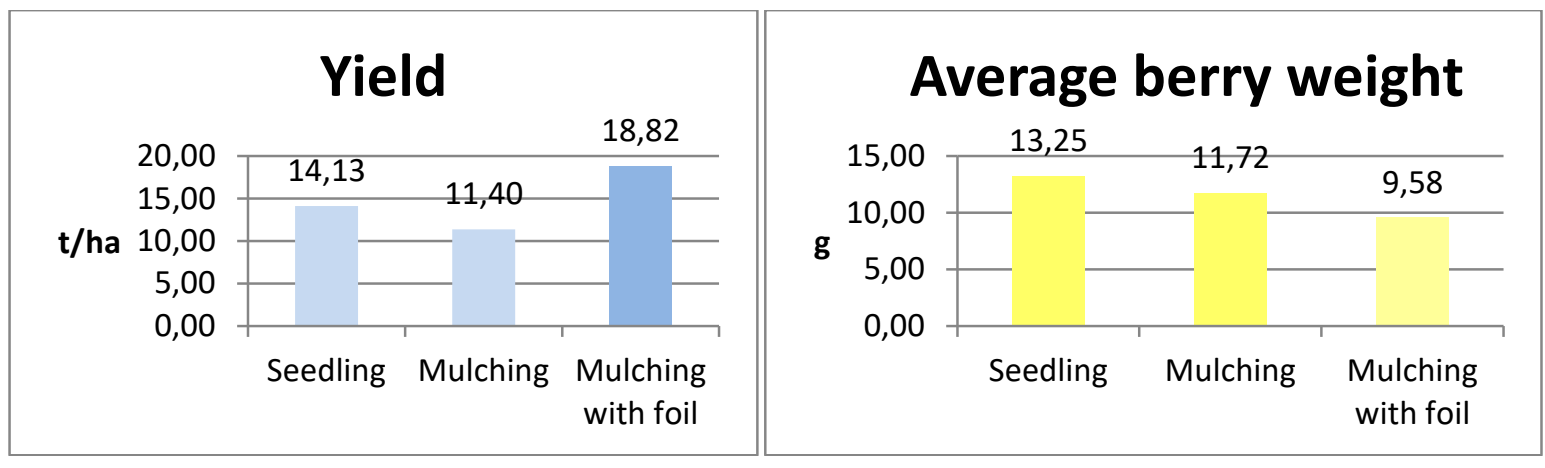

2. Figure Yield

3.Figure Average berry weight

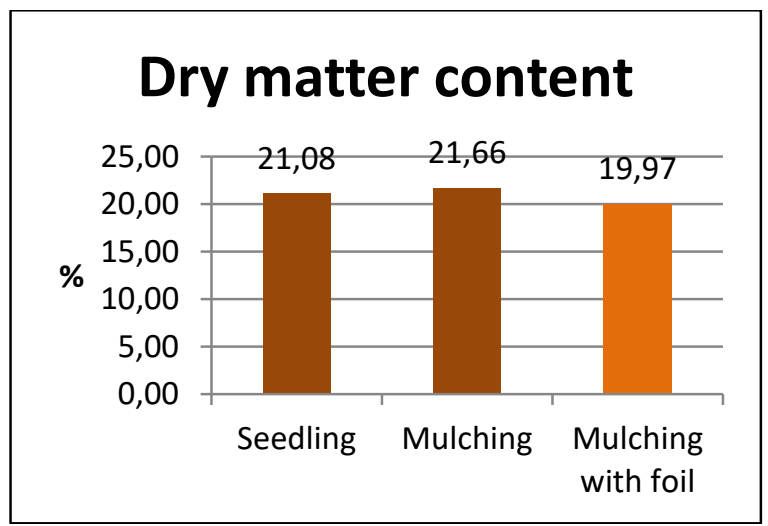

4. Figure Dry matter content

\section{Capsaicinoid content}

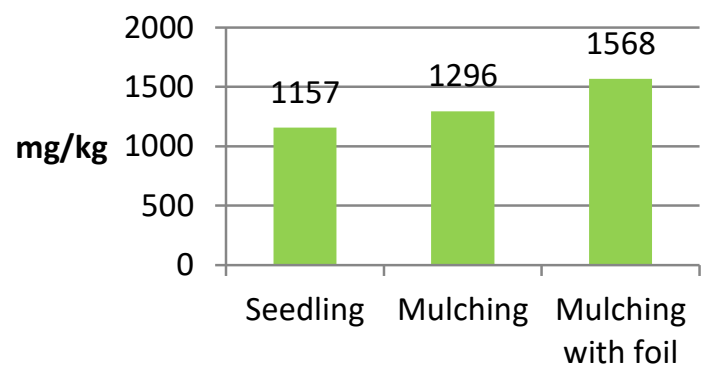

5.Figure Capsaicinoid content

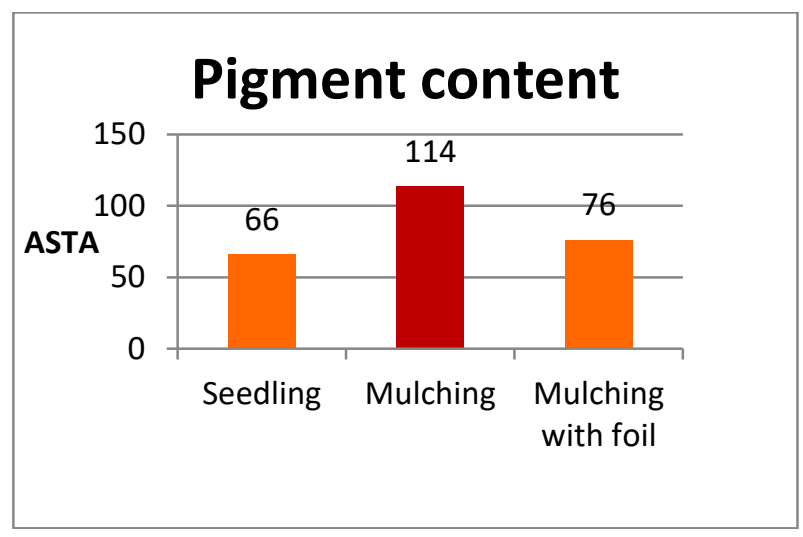

6.Figure Pigment content 


\section{Discussion}

From my experiment it can be stated that the variety cultivated with different technologies produces significant yield and content differences.

The positive effect of the foil is best reflected in the yield data. Here we measured slightly more than 18 tons / ha.

The weight of the berries was the highest at 18.18 grams in the case of the seedling stock.

The capsaicin content of all three technologies exceeded the $200 \mathrm{mg} / \mathrm{kg}$ required for the hot category.

For pigmment content, ASTA values of 54-88 were measured. Based on the requirements of the processing industry, Hetényi Parázs belongs to the sweet-noble category.

When measuring the dry matter content, we found minimal differences between the technologies.

\section{Conclusion}

All in all I can say that the parameters of the examined species meet all the requirements of the processing industry.

\section{Acknowledgment}

This research is supported by EFOP-3.6.1-16-2016-00006 "The development and enhancement of the research potential at John von Neumann University" project. The Project is supported by the Hungarian Government and co-financed by the European Social Fund.

\section{References}

[1] MÁRKUS, F., DAOOD, H. G., KAPITÁNY, J., BIACS, P. A. (1999): Change in the carotenoid and antioxidant content of spice red pepper (paprika) as a function of ripening and some technological factors, Journal of Agricultural and Food Chemistry,47,100-107.p. DOI: http://dx.doi.org/10.1021/jf980485z

[2] Ittah, Y., Kanner, J., Granit, R., 1993. Hydrolysis study of carotenoid pigments of paprika (Capsicum annuum L. variety Lehava) by HPLC/ photodiode array detection. Journal of Agricultural and Food Chemistry 41, 899-901.

[3] Tsuchiya, H., 2001. Biphasic membrane effects of capsaicin, an active component in Capsicum species. Journal of Ethnopharmacology 75, 295-299. 